\title{
Intravenous sotalol for the treatment of atrial fibrillation and flutter after cardiopulmonary bypass Comparison with disopyramide and digoxin in a randomised trial
}

\author{
TERENCE J CAMPBELL, THOMAS P GAVAGHAN, JOHN J MORGAN \\ From the Cardiovascular Unit, St Vincent's Hospital, Sydney, Australia
}

SUMMARY The efficacy of sotalol in treating acute atrial fibrillation and flutter after open heart surgery was compared with that of a digoxin/disopyramide combination. Forty adult patients with postoperative atrial arrhythmias were randomised into either group 1 (sotalol $1 \mathrm{mg} / \mathrm{kg}$ bolus intravenously plus $0.2 \mathrm{mg} / \mathrm{kg}$ intravenously over 12 hours) or group 2 (digoxin $0.75 \mathrm{mg}$ intravenously, then two hours later disopyramide $2 \mathrm{mg} / \mathrm{kg}$ intravenous bolus and $0.4 \mathrm{mg} / \mathrm{kg} / \mathrm{h}$ intravenously for 10 hours). In each group, 17 out of 20 patients reverted to sinus or junctional rhythm within 12 hours. The time to reversion in group 1 was significantly shorter than in group 2 . Systolic blood pressure fell by $\geqslant 20 \mathrm{~mm} \mathrm{Hg}$ or to $\leqslant 90 \mathrm{~mm} \mathrm{Hg}$ during drug administration in 17 out of 20 patients in group 1 (sotalol withdrawn in two) and in none out of 20 in group 2. Two patients in group 1 developed transient bradycardia (sotalol withdrawn in one). None of 17 patients in group 1 and two of 17 in group 2 relapsed temporarily into atrial fibrillation during the 12 hours of intravenous treatment. On continued oral treatment, one late relapse occurred in group 1 and five in group 2, and five patients in group 2 had disopyramide withdrawn because of anticholinergic side effects (acute urinary retention in four).

Sotalol was as effective as the digoxin/disopyramide combination and acted significantly faster. Sensitivity to beta blockade in these patients may be related to high plasma catecholamine concentrations known to occur after cardiopulmonary bypass.

Supraventricular arrhythmias (usually atrial fibrillation or flutter) are common in the first few days after open heart surgery, with reported incidences ranging from $<20 \%$ to $>40 \% .^{1-3}$ While a large proportion of these patients eventually return to sinus rhythm, they present an appreciable postoperative management problem. Treatment with digitalis alone is frequently associated with early reversion to sinus rhythm, but an appreciable number of such patients will remain in atrial fibrillation or flutter, often with a persistent rapid ventricular response, ${ }^{4}$ for long periods.

An earlier study in this institution, where the inci-

Requests for reprints to Dr T J Campbell, Medical Professorial Unit, St Vincent's Hospital, Darlinghurst 2010, Sydney, Australia.

Accepted for publication 29 January 1985 dence of these arrhythmias is $25 \%$, showed a combination of intravenous digoxin and disopyramide to be significantly more effective than digoxin alone in producing early return to sinus rhythm. ${ }^{5}$ This regimen has subsequently been used in over 200 patients with an overall reversion rate of $60 \%$ at 14 hours and $94 \%$ at 10 days. ${ }^{6}$ The incidence of serious side effects (19\%) prompted us to consider alternative drug treatment.

Sotalol is a non-selective beta adrenergic blocking agent with the additional property of producing pronounced prolongation of the duration of the cardiac action potential (Vaughan Williams class III antiarrhythmic action ${ }^{78}$ ). The aim of the present study was to compare the efficacy and side effects of sotalol with those of the digoxin/disopyramide combination in adult patients with acute atrial fibrillation or flutter after open heart surgery. 


\section{Patients and methods}

All patients undergoing cardiac surgery during the period November 1983 to May 1984 who developed postoperative atrial arrhythmias with a ventricular rate of $>120$ beats/min were considered for the study. Criteria for exclusion were a history of glaucoma or asthma, severe renal impairment (serum creatinine concentration $>0.24 \mathrm{mmol} / \mathrm{l}$ ), preoperative atrial arrhythmias or atrioventricular block (second or third degree), and the administration of any antiarrhythmic drug (including beta blockers and digitalis) in the previous 48 hours.

If the arrhythmia persisted for at least 15 minutes eligible patients were then randomly assigned, by a sealed envelope system, to either of two groups. The patients in group 1 were given sotalol (Sotacor, Bristol-Myers) $1 \mathrm{mg} / \mathrm{kg}$ as an intravenous bolus and then a further $0.2 \mathrm{mg} / \mathrm{kg}$ intravenously, given as a continuous infusion in 5\% dextrose, over 12 hours. Group 2 received digoxin $0.75 \mathrm{mg}$ intravenously as a bolus. If they reverted to sinus rhythm within two hours they continued to receive digoxin $0.25 \mathrm{mg}$ intravenously twice a day. If not, disopyramide $2 \mathrm{mg} / \mathrm{kg}$ intravenously (maximum $150 \mathrm{mg}$ ) was then given over 10 minutes followed by an intravenous infusion (in $5 \%$ dextrose) at $0.4 \mathrm{mg} / \mathrm{kg} / \mathrm{h}$ for 10 hours. Written informed consent was obtained from patients allocated to group 1 but not from those in group 2 since they were receiving the standard treatment for such arrhythmias in this institution.

Although the formal comparison between the two treatment regimens ended after 12 hours of intravenous treatment, those patients in group 1 who reverted to sinus rhythm continued to take oral sotalol $160 \mathrm{mg}$ twice daily for the rest of their stay in hospital and for two to three weeks after discharge. Similarly, patients who reverted with digoxin alone continued taking oral digoxin $0.25 \mathrm{mg} /$ day, and those who reverted with the digoxin/disopyramide combination continued taking oral digoxin $0.25 \mathrm{mg} /$ day and disopyramide $150 \mathrm{mg}$ four times a day. The treatment of patients whose arrhythmia persisted at 12 hours was at the discretion of the attending cardiologist and usually consisted of digoxin and either disopyramide or quinidine.

Blood pressure was measured every one to two minutes for 10 minutes, then every 15 minutes for one hour, and then every hour for 12 hours. The electrocardiogram was monitored continuously on a screen, and rhythm strips were recorded at the time of rhythm changes. Twelve lead electrocardiograms were recorded before and 12-24 hours after completion of intravenous treatment. Patients receiving sotalol had blood collected for determining plasma concentrations of the drug at one hour and 12 hours. Assays of plasma disopyramide concentrations were
Table 1 Details of patients

\begin{tabular}{|c|c|c|}
\hline & Group 1 & Group 2 \\
\hline $\begin{array}{l}\text { No of patients } \\
\text { Male:female ratio } \\
\text { Mean (SD) age (yr) } \\
\text { Mean (SD) time to onset of } \\
\text { arrhythmia (hr) } \\
\text { Ratio of atrial fibrillation: } \\
\text { atrial flutter } \\
\text { Mean (SD) pretreatment systolic } \\
\text { pressure (mm Hg) } \\
\text { Mean (SD) pretreatment ventricular } \\
\text { rate (beats/min) } \\
\text { No taking beta blockers } \\
\text { preoperatively } \\
\text { No undergoing coronary artery } \\
\text { bypass graftingt } \\
\text { No with preoperative ejection } \\
\text { fraction <0.50ł }\end{array}$ & $\begin{array}{l}20 \\
19: 1 \\
60 \cdot 5(9 \cdot 1) \\
54 \cdot 4(16) \\
19: 1 \\
114(12) \\
163(24) \\
15 \\
17 \\
2\end{array}$ & $\begin{array}{l}20 \\
15: 5 \\
63 \cdot 5(5 \cdot 2) \\
55 \cdot 1(27 \cdot 7) \\
19: 1 \\
112(10) \\
158(17) \\
15 \\
16 \\
2\end{array}$ \\
\hline
\end{tabular}

*Estimated as time from start of cardiopulmonary bypass till onset of index arrhythmias.

tOther operations-Group 1: two patients had coronary artery bypass grafting (CABG), plus carotid endarterectomy and one had ventriculomyotomy for hypertrophic cardiomyopathy; group 2: one had CABG and carotid endarterectomy, one aortic valve replacement, one repair of ruptured papillary muscle, and one repair of ascending aortic aneurysm.

$\ddagger$ At left ventriculography.

not performed in all group 2 patients as the regimen used has been previously shown to produce concentrations in the therapeutic range in similar patients. ${ }^{5}$

\section{STATISTICAL ANALYSIS}

Unless otherwise stated, results are given as mean (standard deviation of the mean (SD)). Student's $t$ tests were used to test for significance of differences in reversion times and corrected QT intervals (QTc) before and after treatment. The $\chi^{2}$ test (using Yates's correction factor) was used to test the significance of differences in relapse rates between the two groups.

\section{Results}

\section{ANTIARRHYTHMIC EFFICACY}

Of 42 eligible patients, 22 were randomised to group 1 and 20 to group 2. One of the group 1 patients refused consent and was given standard treatment (reverted to sinus rhythm after 72 hours), and one reverted spontaneously to sinus rhythm before any sotalol was given. These two patients were excluded from the analysis.

Table 1 shows the clinical details of the remaining 40 patients. Sixteen of the 20 patients in group 1

Table 2 Results

\begin{tabular}{llll}
\hline & Group 1 & Group 2 & p value \\
\hline $\begin{array}{l}\text { Reversion within 12 hr } \\
\begin{array}{l}\text { Mean (SD) time to } \\
\text { reversion (min) }\end{array}\end{array}$ & 17 & 17 & NS \\
$\begin{array}{l}\text { Relapse within 12 hr } \\
\text { Relapse beyond 12 hr }\end{array}$ & $58.8(68)$ & $187(164)$ & $<0.01$ \\
\hline
\end{tabular}




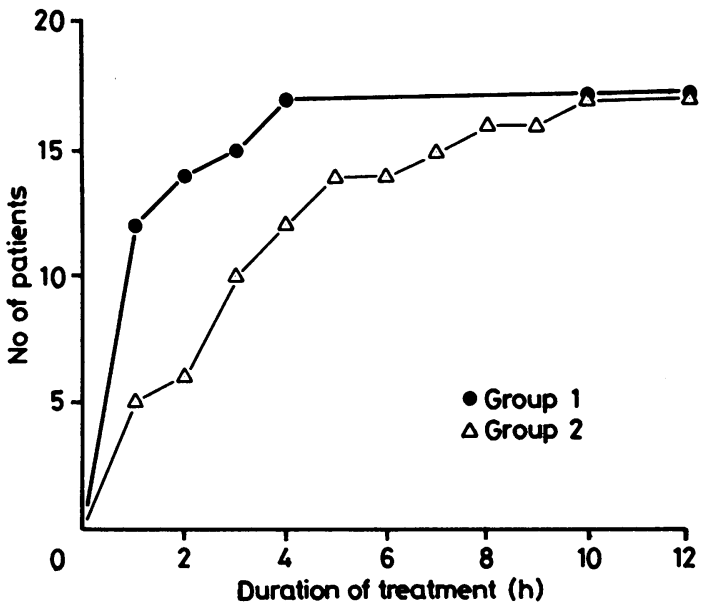

Figure Time course of reversion from atrial fibrillation to sinus rhythm in patients treated with sotalol (group $1, n=20$ ) and with a digoxin/disopyramide combination (group $2, n=20$ ). One patient in group 1 reverted first to junctional rhythm and then to sinus rhythm (see text).

reverted to sinus rhythm, and one reverted to junctional rhythm (see below) during the 12 hours of intravenous sotalol treatment (Table 2). The times from starting the sotalol bolus infusion to reversion ranged from 5 to 225 (mean 58.8 (67.7)) minutes and included 12 patients who reverted within the first hour (Figure). Plasma concentrations of sotalol were $908(326) \mathrm{ng} / \mathrm{ml}$ at one hour and fell to $372(154) \mathrm{ng} /$ $\mathrm{ml}$ at 12 hours.

Of the three patients who failed to revert, only one received the full dose of sotalol. One patient (who had atrial flutter) was given only $40 \mathrm{mg}$ of a planned $84 \mathrm{mg}$ bolus of sotalol, at which time his systolic blood pressure had fallen from $130 \mathrm{~mm} \mathrm{Hg}$ to $70 \mathrm{~mm} \mathrm{Hg}$, and the drug was withdrawn (see below). He was then given digoxin and disopyramide, and his systolic blood pressure returned to $130 \mathrm{~mm} \mathrm{Hg}$ over the next two hours. The arrhythmia persisted for the next six days despite continued treatment with digoxin, disopyramide, and, later, quinidine, and he underwent $\mathrm{DC}$ cardioversion at that time. A second patient had received $50 \mathrm{mg}$ of a planned $74 \mathrm{mg}$ bolus

Table 3 Major side effects

\begin{tabular}{lll}
\hline & Group 1 & Grous 2 \\
\hline Hypotension* & 17 & 0 \\
Bradycardia & 2 & 0 \\
Ventricular tachycardia & 0 & 1 \\
Urinary retention & 0 & 4 \\
Drug withdrawn $<12 \mathrm{hr}$ & 3 & 0 \\
Drug withdrawn $>12 \mathrm{hr}$ & 1 & 6 \\
\hline
\end{tabular}

«Defined as a fall in systolic blood pressure of at least $20 \mathrm{~mm} \mathrm{Hg}$ or to $<90 \mathrm{~mm} \mathrm{Hg}$. of sotalol when his electrocardiographic monitor lead configuration was changed from standard lead I to lead II and ST segment elevation noted. Sotalol was withdrawn, although the ST elevation subsequently proved to be due to postoperative pericarditis. This patient was then given standard treatment and reverted to sinus rhythm during the disopyramide bolus infusion. The third patient remained in atrial fibrillation despite the full 12 hours of sotalol treatment. He returned to sinus rhythm three hours after starting oral digoxin.

In group 2, 17 out of 20 patients reverted to sinus rhythm within 12 hours (Table 2). The times from digoxin bolus to reversion ranged from 5 to 450 (mean 187.7 (164)) minutes and included five patients who returned to sinus rhythm within one hour (Figure). These times were significantly longer than those for group $1(p<0.01)$. There were six patients who reverted with digoxin alone (at 38.0 (33.7) minutes after the digoxin bolus) and 11 who required the combination of digoxin and disopyramide (reverting 176.6 (200) minutes after disopyramide). The three patients in group 2 whose arrhythmia persisted at 12 hours eventually reverted to sinus rhythm after 19 hours, 20 hours, and 72 hours of continued treatment with digoxin and oral disopyramide.

No patient in group 1 relapsed during the 12 hours of intravenous sotalol, but one who had returned to sinus rhythm four hours after starting sotalol relapsed 19 hours later. Sotalol was continued, and he reverted permanently to sinus rhythm after a further seven hours. A second patient in group 1 relapsed 13 hours after sotalol had been withdrawn, after the development of junctional bradycardia (see below).

Four patients who responded to digoxin alone relapsed 30 minutes to 57 hours later (Table 2). Three were then given disopyramide and one quinidine, and all returned quickly to sinus rhythm. Three patients (out of 11) who responded initially to digoxin plus disopyramide relapsed at 90 minutes, 30 hours, and 32 hours. Two were restored to sinus rhythm soon after a further bolus of intravenous digoxin $(0.25 \mathrm{mg})$, and the third returned to sinus rhythm 30 minutes after starting oral quinidine.

\section{SIDE EFFECTS (TABLE 3)}

An appreciable fall in blood pressure was seen during the initial intravenous loading dose of sotalol in 18 out of 20 patients in group 1 (Table 3). In 17 of these, systolic blood pressure fell by at least $20 \mathrm{~mm} \mathrm{Hg}$ or fell to $90 \mathrm{~mm} \mathrm{Hg}$ systolic or lower. No patient developed symptoms attributable to hypotension, and in all but two cases (see below) the blood pressure returned towards pretreatment levels over one to two hours despite continued sotalol infusion. Sotalol was withdrawn because of this hypotensive response in 
two patients. One (who has been mentioned already) had received only $40 \mathrm{mg}$ of a planned $84 \mathrm{mg}$ bolus, by which time his systolic blood pressure had fallen from $130 \mathrm{~mm} \mathrm{Hg}$ to $70 \mathrm{~mm} \mathrm{Hg}$ and sotalol was withdrawn. The blood pressure returned to $130 \mathrm{~mm} \mathrm{Hg}$ over the next two hours. The other patient had sotalol withdrawn after 12 hours, during which his systolic blood pressure, which had been $100 \mathrm{~mm} \mathrm{Hg}$ before treatment, remained $80-85 \mathrm{~mm} \mathrm{Hg}$.

Two patients developed bradycardia during intravenous sotalol administration. One reverted from atrial fibrillation with a very rapid ventricular rate of $>250$ beats/min into a junctional bradycardia (50 beats/min) after receiving $50 \mathrm{mg}$ of a projected $90 \mathrm{mg}$ bolus of sotalol. He remained asymptomatic, but sotalol was withdrawn. The junctional rhythm persisted for a further 12 hours, by which time the rate was 90 beats/min. Atrial fibrillation then returned and remained for a further nine hours, during which time $1 \mathrm{mg}$ of intravenous digoxin was given before sinus rhythm was finally restored. Unfortunately, during this second period of atrial fibrillation the patient developed a right hemiparesis of very sudden onset, which proved to be permanent. The second patient reverted to sinus rhythm during the bolus ( $64 \mathrm{mg}$ ) of sotalol but showed several asymptomatic periods of sinus arrest, lasting up to three seconds, over the ensuing 30 minutes. Stable sinus rhythm then returned at a rate of 75 beats $/ \mathrm{min}$. Sotalol was not withdrawn, and no further complications were seen.

Sotalol was withdrawn in a fourth patient (who has already been reported) when ST segment elevation, later found to be due to pericarditis, was noted during the bolus injection. No other complications were experienced with sotalol.

There were no appreciable side effects in group 2 patients during the 12 hours of intravenous treatment. There was a statistically significant fall in systolic blood pressure in those 14 patients who received disopyramide (from 113(11) $\mathrm{mm} \mathrm{Hg}$ to $107(12) \mathrm{mm} \mathrm{Hg}$; $\mathrm{p}<0.05$ ), but in no case was a fall of $>15 \mathrm{~mm} \mathrm{Hg}$ recorded. Five patients had disopyramide withdrawn after six to 72 hours of oral treatment because of anticholinergic side effects (acute urinary retention in four, dry mouth in one). One patient who reverted to sinus rhythm 20 hours after starting disopyramide had an episode of sustained ventricular tachycardia requiring electrical cardioversion after a further seven hours of oral disopyramide. This arrhythmia did not resemble torsade de pointes, nor was there abnormal prolongation of the $\mathrm{QT}$ interval on the electrocardiogram. Disopyramide was, however, withdrawn, and there was no recurrence of ventricular arrhythmia.

The corrected QT interval (QTc) was prolonged by both disopyramide and sotalol. The value of this interval increased from $0.43(0.05)$ to $0.47(0.03)$ ( $p<$
0.01 ) in the 16 group 1 patients who received sotalol for at least 24 hours. Those receiving disopyramide showed a less pronounced increase in QTc from $0.42(0.02)$ to $0.44(0.04)(p<0.01 ; n=15)$. The longest QTc interval measured was 0.51 (in a group 1 patient).

\section{Discussion}

There are several reasons for supposing that sotalol might be an effective agent for reversion of postoperative atrial tachyarrhythmias. As a non-selective beta blocker it would be expected to have some antiarrhythmic potential and would tend to slow atrioventricular conduction rather than enhance it, a potential danger with disopyramide. ${ }^{y}$ More importantly, sotalol, uniquely among beta blockers, possesses a potent class III antiarrhythmic action ${ }^{7}$ and has shown considerable antiarrhythmic efficacy in several studies. ${ }^{10-12}$

In this randomised trial, treatment with sotalol proved to be as effective as the digoxin/disopyramide combination in returning patients to sinus rhythm. Furthermore, it acted significantly more quickly and was associated with fewer relapses during the follow up period. The reversion rate of 17 out of $20(85 \%)$ patients after 12 hours of digoxin/disopyramide was higher than the $60 \%$ at 14 hours previously observed by us in a much larger group of patients. ${ }^{6}$ The incidence of side effects requiring drug withdrawal $(5 / 20)$ was similar to our previous experience, although all these events occurred after the 12 hour period of intravenous treatment, as did five of the seven relapses observed. Side effects, particularly hypotension, were, unfortunately, a major drawback with sotalol too, and warrant futher discussion.

Sotalol has been given intravenously in similar doses to other groups of patients without reports of such effects on blood pressure. ${ }^{10}$ It is known, however, that serum concentrations of adrenaline and noradrenaline rise appreciably at the time of open heart surgery and remain high for two to three days postoperatively. ${ }^{13}$ Furthermore, a recent animal study has shown activation of the sympathoadrenal system, leading to a pronounced increase in plasma catecholamine concentrations during experimentally induced atrial fibrillation. ${ }^{14}$ It is possible that these phenomena make such patients peculiarly susceptible to the acute hypotensive effects of beta blockade. Whatever the cause of the hypotension, simply reducing the dosage of sotalol is unlikely to remove the problem, as pronounced falls in blood pressure were routinely observed within two to three minutes of starting the bolus dose (given over 10 minutes). A possible alternative approach would be to give the same loading dose as an infusion over one hour rather 
than as a bolus. Given the long plasma half life of sotalol 15 this would be unlikely to lead to appreciably lower plasma drug concentrations at steady state.

Finally, the serum sotalol concentrations obtained were lower than those reported in other studies both of short term intravenous and long term oral administration. ${ }^{11} 12$ They were all within the range regarded as producing beta blockade but generally at the lower end of the range of concentrations found to produce a pronounced class III effect. ${ }^{16}$ The first measurement of sotalol concentration was not, however, made until one hour after the administration of the bolus, by which time 12 out of 17 reversions had already occurred. Considerably higher blood concentrations of the drug were probably achieved in the 10 to 20 minutes immediately after the bolus dose.

We thank Mr J Ray for performing the plasma sotalol assays.

\section{References}

1 Johnson LW, Dickstein RA, Fruehan CT, et al. Prophylactic digitalization for coronary artery bypass surgery. Circulation 1976; 53: 819-22.

2 Kempf FC, Hedberg A, Molinoff P, Josephson ME. The relation of atrial beta receptor density to post-operative arrhythmias [Abstract]. $\mathcal{F}$ Am Coll Cardiol 1984; 3: 487.

3 Stephenson LW, MacVaugh H, Tomasello DN, Josephson ME. Propranolol for prevention of postoperative cardiac arrhythmias: a randomized study. Ann Thorac Surg 1980; 29: 113-6.

4 Weiner P, Bassan MM, Jarchovsky J, Iusim S, Plavnick L. Clinical course of acute atrial fibrillation treated with rapid digitalization. Am Heart $\mathcal{f}$ 1983; 105: 223-7.

5 Campbell TJ, Morgan JJ. Treatment of atrial arrhythmias after cardiac surgery with intravenous disopyramide. Aust NZ F Med 1980; 10: 644-9.
6 Gavaghan TP, Feneley MP, Campbell TJ, Morgan JJ. Atrial tachyarrhythmias after cardiac surgery: results of disopyramide therapy. Aust NZ $\mathcal{F}$ Med 1985; 15: 27-32.

7 Singh BN, Vaughan Williams EM. A third class of antiarrhythmic action. Effects on atrial and ventricular intracellular potentials, and other pharmacological actions on cardiac muscle, of MJ1999 and AH3474. Br F Pharmacol 1970; 39: 675-87.

8 Touboul P, Atallah G, Kirkorian G, Lamaud M, Moleur P. Clinical electrophysiology of intravenous sotalol, a beta-blocking drug with class III antiarrhythmic properties. Am Heart $\mathcal{f}$ 1984; 107: 888-95.

9 Birkhead JS, Vaughan Williams EM. Dual effect of disopyramide on atrial and atrioventricular conduction and refractory periods. $\mathrm{Br}$ Heart $\mathcal{f}$ 1977; 39: 657-60.

10 Latour Y, Dumont G, Brosseau A, Lelorier J. Effects of sotalol in twenty patients with cardiac arrhythmias. International fournal of Clinical Pharmacology and Biopharmacy 1977; 15: 275-8.

11 Senges J, Lengfelder W, Jauernig R, et al. Electrophysiologic testing in assessment of therapy with sotalol for sustained ventricular tachycardia. Circulation 1984; 69: 577-84.

12 Rizos I, Senges J, Jauernig R, et al. Differential effects of sotalol and metoprolol on induction of paroxysmal supraventricular tachycardia. Am f Cardiol 1984; 53: 1022 7.

13 Engelman RM, Haag B, Lemeshow S, Angelo A, Rousou JH. Mechanism of plasma catecholamine increases during coronary artery bypass and valve procedures. $\mathcal{F}$ Thorac Cardiovasc Surg 1983; 86: 608-15.

14 Wichmann J, Ertl G, Höhne W, Schweisfurth H, Wernze H, Kochsiek K. Alpha-receptor restriction of coronary blood flow during atrial fibrillation. Am $\mathcal{F}$ Cardiol 1983; 52: 887-92.

15 Frishman W. Clinical pharmacology of the new betaadrenergic blocking drugs. Part I. Pharmacodynamic and pharmacokinetic properties. Am Heart $\mathcal{f}$ 1979; 97: 663-70.

16 Neuvonen PJ, Elonen E, Tanskanen A, Toumilehto J. Sotalol and prolonged Q-Tc interval [Letter]. Lancet 1981; ii: 426. 